\title{
Top-down control over involuntary attention switching in the auditory modality
}

\author{
E. SUSSMAN \\ Albert Einstein College of Medicine, Bronx, New York \\ I. WINKLER \\ Hungarian Academy of Sciences, Budapest, Hungary \\ and University of Helsinki, Helsinki, Finland
}

and

E. SCHRÖGER

University of Leipzig, Leipzig, Germany

\begin{abstract}
We tested the effects of predictability on involuntary attention switching to task-irrelevant sound changes (distraction). Behavioral and neurophysiological evidence are provided, showing that the predictability of task-irrelevantsound changes eliminates effects of distraction even though the automatic auditory change detection system remains responsive. Two indices of distraction, slower task performance and cortical brain responses associated with attention switching, were seen only in the unpredictable condition, in which the irrelevant acoustic changes were unexpected. Attention was not involuntarily drawn away from the primary task when the subjects had foreknowledge of when the irrelevant changes would occur. These results demonstrate attentional control over orienting to sound changes and suggest that involuntary attention switching occurs mainly when an irrelevant stimulus change is unexpected. The present data allowed observation of the temporal dynamics of attention switching in the human brain.
\end{abstract}

The ability to focus on a single task and to filter out irrelevant environmental events is a fundamental capability of the human attentional system. When a task-irrelevant change in ongoing stimuli occurs, it elicits an involuntary shift of attention. This attentional capture may be a way of alerting an organism to a potentially significant event so that further evaluation of its relevance can be made. In the visual modality, the effects of attentional capture have been studied extensively, using visual search type paradigms. When a target in a search display contains an item that is unique in some feature (e.g., a red square among blue squares), this salient feature singleton seems to $p o p$ out of the display, making search efficient. If, however, the unique feature singleton that pops out in the display is irrelevant to the search task (i.e., nontarget), the salient feature distracts the subject from the primary task. The popout phenomenon of the single feature is thought to be a function of preattentive processing (Treisman, \& Gelade, 1980), suggesting that this type of distraction is stimulus

This research was supported by National Institutes of Health Grant R01 DC04263, the Hungarian National Research Fund (OTKA T034112), the Deutsche Forschungsgemeinschaft(DFG), and the DAAD. We thank Robert J. Ruben for his helpful comments on an earlier version of the manuscript. Correspondence concerning this article should be addressed to E. Sussman, Department of Neuroscience, Albert Einstein College of Medicine, 1410 Polham Parkway S., Bronx, NY 10461 (e-mail: esussman@aecom.yu.edu). driven (Theeuwes, 1992, 1994; Yantis, 1993; Yantis \& Jonides, 1984). Under most circumstances, effects of attentional capture on task performance are induced by the presence of irrelevant but salient stimulus features in the display. Feature singletons can capture attention even when they occur on an irrelevant stimulus dimension (Theeuwes \& Berger, 1998). Moreover, the salient external events still produce involuntary orienting to them and affect performance despite instructions given in advance to ignore the irrelevant dimension (Folk \& Remington, 1996; Remington, Johnston, \& Yantis, 1992) or location (Müller \& Rabbitt, 1989). This would suggest that attentionalcapture is completely stimulus driven and cannot be controlled by top-down processes (Theeuwes, 1991, 1992, 1994; Yantis \& Jonides, 1984).

There is considerable debate, however, about whether or not attentional capture, in visual search and cuing paradigms, can be modified by top-down control (Folk, Remington, \& Johnston, 1992; Remington, Folk, \& McLean, 2001; Yantis, 1993; Yantis \& Egeth, 1999; Yantis \& Jonides, 1990). Folk and colleagues suggest that a top-down attentional set always exerts some influence on stimulus-driven processes. They suggest that the subject's attentional set biases performance, so that only feature changes that are part of the target features can exert attentional capture (Driver \& Baylis, 1991; Folk et al., 1992; Kramer \& Jacobson, 1991; Remington et al., 2001; Theeuwes \& Berger, 1998; cf. Jonides \& Yantis, 1988). 
Yantis and colleagues demonstrated that attentional capture by abrupt visual onsets in cuing paradigms are subject to top-down control under certain circumstances (Yantis \& Jonides, 1990), that they do not capture attention in a strictly automatic fashion, such as under conditions of highly focused attention (Yantis \& Egeth, 1999), and that, contrary to Folk, they can capture attention even when a specific prior state for them is not established (Jonides \& Yantis, 1988).

The effects of attentional capture (or distraction) for the auditory modality have not been as well defined as those for the visual modality. Effects of attention capturing on task performance by irrelevant sound changes have been shown (for a review, see Escera, Alho, Schröger, \& Winkler, 2000) to be similar to those in the visual modality. This has been demonstrated behaviorally, by the prolongation of response times (RTs) to target tones that also contain sound changes on an irrelevant dimension and by the presence of an involuntary orienting response evoked by irrelevant sound changes, when the primary task was either visual (e.g., Alho, Escera, Diaz, Yago, \& Serra, 1997) or auditory (e.g., Schröger \& Wolff, 1998b). However, top-down effects on attentional capture, such as the ability to filter out irrelevant sound changes occurring in an irrelevant sound dimension, have not been explored.

Previous studies have examined the effects of attention switching only to infrequent irrelevant sound changes that occurred randomly within a sound sequence (i.e., they could not be predicted on any given trial). It is not known, therefore, whether the observed effects of attention switching invoked by the feature change occurs automatically for every irrelevant sound change, whether or not the stimulus dimension is relevant or irrelevant (i.e., is an involuntary response to environmental change), or whether, in the auditory modality, attention switching occurs only for randomly occurring irrelevant changes (i.e., because they are unexpected).

In the present study, we hypothesized that attention switching occurs involuntarily because the event is unexpected and, therefore, further evaluation of the acoustic environment is required. If every irrelevant change were predictable, further evaluation would not be necessary. Therefore, by simultaneously measuring behavioral and electrophysiologicalindices of distraction, we tested whether top-down processes can control the involuntary orienting of attention to irrelevant sound changes and, in so doing, eliminate cost of performance of the main task.

Behaviorally, orienting to irrelevant events has been observed as a slowing down of performance in a primary task (e.g., as an increase of the RT to targets by about $40 \mathrm{msec}$ ). The cost in performance on the primary task, attributable to the momentary shift of attention away from the primary task (Theeuwes, 1992) or to the cost of filtering out the irrelevant sensory information (Folk \& Remington, 1998), has been called a distraction effect (e.g., Schröger \& Wolff, 1998b; Theeuwes, 1992).

Event-related brain potentials (ERPs) have been used extensively to index the cognitive processes initiated by sound change. ERPs provide high temporal resolution, in the order of milliseconds, allowing us to examine the progression of neural responses to an auditory stimulus. When the stimulus-driven detection of a sound change initiates an attention switch to an acoustic event and a subsequent reorienting to the main task, a series of cognitive processes can be observed in the succession of the associated brain components: mismatch negativity (MMN), $\mathrm{P} 3 \mathrm{a}$, and reorienting negativity (RON), respectively. The association of the processes with the brain components is described below.

\section{MMN}

Stimulus-driven sound change detection is reflected by the MMN component. The change detection process underlying MMN generation uses the sensory representation of the acoustic regularities extracted from the sound sequence. Sounds that do not match with the neural trace of these regularities elicit MMN (occurring about $150 \mathrm{msec}$ from stimulus onset), whether or not attention is focused on the sounds (for reviews, see Näätänen \& Winkler, 1999; Picton, Alain, Otten, Ritter, \& Achim, 2000). Infrequent sound changes occurring in any stimulus dimension, either task-relevant or task-irrelevant, elicit MMN. The MMN response, with the main generators in the auditory cortex (Csépe, Karmos, \& Molnar, 1987; Giard, Perrin, Pernier, \& Bouchet, 1990; Halgren et al., 1995; Javitt, Steinschneider, Schroeder, \& Arezzo, 1996; Kropotov et al., 1995; Sams \& Hari, 1991; Scherg, Vajsar, \& Picton, 1989), may be followed by frontal activation (Opitz, Rinne, Mecklinger, von Cramon, \& Schröger, 2002; Rinne, Alho, Ilmoniemi, Virtanen, \& Näätänen, 2000), possibly providing a link to the generators of the subsequent sequence of brain responses associated with auditory distraction (P3a and RON).

\section{P300}

Involuntary attention switching to sounds elicits the P3a component (or novelty P3), which follows the MMN in time, occurring around $270 \mathrm{msec}$ from stimulus onset (see Friedman, Cycowicz, \& Gaeta, 2001, for a review). P3a is elicited by infrequent or novel sounds presented within a sequence of frequently occurring sounds (e.g., the auditory $90 \%-10 \%$ auditory oddball paradigm) or by a sound occurring after a long silence. As with MMN, P3a can be elicited by deviations in a sound sequence even when attention is not focused on the sounds. However, an important distinction is that the P3a component is thought to reflect the action of attention switching, whereas the MMN is thought to reflect the detection of the deviance (for reviews, see Escera et al., 2000; Friedman et al., 2001; Knight \& Scabini, 1998; Woods, 1990). The P3b component (or target P3; Sutton, Braren, Zubin, \& John, 1965) is also elicited by infrequent stimuli; however, unlike P3a, the stimulus must be task relevant for P3b to be evoked. $\mathrm{P} 3 \mathrm{~b}$ is generally associated with context updating (Donchin $\&$ Coles, 1988) and usually has a more posterior scalp distribution than does P3a. The amplitude of P3b can reflect the amount of information extracted from the rare stimulus event. The more information extracted, the larger the $\mathrm{P} 3$. Some distinguish the P3 elicited by novels (P3a) from 
the P3 elicited by targets (P3b; Courchesne, Hillyard, \& Galambos, 1975; N. K. Squires, K. C. Squires, \& Hillyard, 1975), whereas others consider them aspects of the same P300 component (Spencer, Dien, \& Donchin, 1999).

\section{RON}

Turning attention back to the primary task after it has been oriented away is indexed by a later negative deflection (occurring around $500 \mathrm{msec}$ from stimulus onset) termed RON (Ahveninen et al., 2000; Berti \& Schröger, 2001; Escera, Yago, \& Alho, 2001; Schröger, Giard, \& Wolff, 2000; Schröger \& Wolff, 1998a). RON is elicited only by task-irrelevant sound changes, following P3a in time. It is thought to reflect reorienting back to taskrelevant information. The generators of $\mathrm{P} 3 \mathrm{a}$ and $\mathrm{RON}$ are partly located in prefrontal areas of the cortex (Schröger et al., 2000), which is consistent with the putative function of these components in the control of attention (e.g., Knight, 1991). The antero-dorsal prefrontal cortex, for example, has been implicated in the shifting of attention between different perceptual dimensions of visual objects (color and shape; Nagahama et al., 2001).

We presented pairs of visual and auditory stimuli (see Figure 1) in two conditions (predictable and unpredictable) in order to test the hypothesis that predictable sound changes can avert attention switching. In both conditions, the subjects' task was to determine the length of the tone on each trial, by pressing a response key to the longer duration tones. Occasionally, the pitch of a tone, which was irrelevant for the task (and the subjects were instructed to ignore the pitch changes), was different from the rest of the tones. In the predictable condition, the visual stimuli indicated the pitch of the tones. In the unpredictable condition, the visual stimuli were randomly paired with the auditory stimuli and were not associated with the pitch of the tones. Only in the predictable condition were the subjects informed by the visual stimulus about the pitch of the tone prior to its onset and so were able to use this information to ignore the upcoming irrelevant change and, thus, focus only on the duration of the tone. The visual stimuli did not predict the duration of the tone in either condition. If the distraction effect can be reduced or eliminated by foreknowledge of the occurrence of an irrelevant acoustic change, only in the unpredictable condition should we see signs of distraction: increased RTs to deviantpitched tones, as well as the brain responses associated with attention switching (P3a) and reorienting back to the main task (RON).

\section{METHOD}

\section{Subjects}

Nine right- and 2 left-handed healthy adults ( 8 females and 3 males, ranging in age from 20.4 to 44.2 years; mean age, 30.8 years, $S D=$ 8.1) were paid for their participation. The data from 2 subjects were excluded from the analysis due to behavioral performance that was below 50\% correct responses in one or both of the experimental conditions. The study was conducted at the Albert Einstein College of Medicine.

\section{Stimuli and Procedure}

The subjects were seated in a comfortable chair $1.3 \mathrm{~m}$ from a video monitor in a sound-attenuated recording cabin. Fifty percent of the tones were $100 \mathrm{msec}$ in duration, and $50 \%$ were $200 \mathrm{msec}$ in duration. The subjects were instructed to fixate at a white cross in the center of the screen and to press a response key to the longer tones. Of the tones, $87.5 \%$ were $440 \mathrm{~Hz}$ (standards), and $12.5 \%$ were $494 \mathrm{~Hz}$ (deviants), randomized across all of the tones. Visual stimuli were colored squares (100-msec duration) and were matched for luminance. Red squares appearing $3 \mathrm{~cm}$ below the fixation cross were presented on $87.5 \%$ of the trials, and green squares appearing $3 \mathrm{~cm}$ above the fixation cross on were presented $12.5 \%$ of the trials. Visual and auditory stimuli were presented in pairs, with $350 \mathrm{msec}$ between the onsets of the visual and the auditory stimuli. The interpair interval between the visual and auditory stimulus pairs was $750 \mathrm{msec}$ (offset to onset). The order of the visual stimuli was randomized in both conditions. In the unpredictable condition, the visual stimulus only provided information that a tone would follow and was not associated with the pitch of the tone. The subjects were so informed and were instructed to ignore the pitch in performing the duration discrimination task. In the predictable condition, red squares were paired with the low-pitched tones, and green squares were paired with the high-pitched tones. Thus, the visual stimulus provided two cues: It informed the subject that a tone would follow, and it informed the subject about the pitch of the tone. Even though information about the pitch of the tone in itself was irrelevant to the task, the subjects were instructed to use this information so as to better ignore the pitch of the tones to maximize their performance in the duration discrimination task.

Two thousand four hundred visual-auditory stimulus pairs were presented (1,200 pairs per condition), in separately randomized runs of 400 pairs each (three runs per condition). For each condition, there were 600 trials (i.e., long tones); 75 of these trials also had a deviant pitch. The testing session lasted about $2 \mathrm{~h}$, which consisted

\section{STIMULUS PARADIGM}

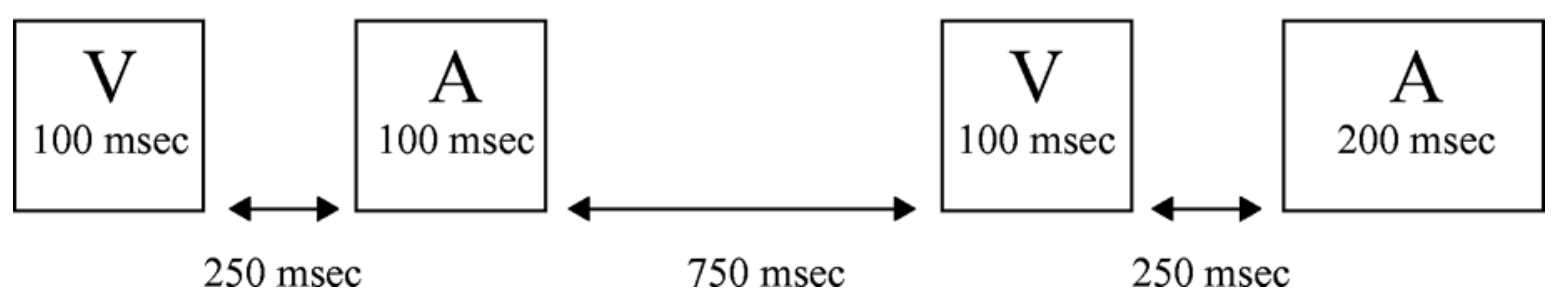

Figure 1. Stimulus paradigm: Schematic illustration showing the timing and presentation of the visual (V) and auditory (A) stimulus pairs. 
of $1 \mathrm{~h}$ of recording time and one long $(\sim 15 \mathrm{~min})$ and two short $(\sim 5 \mathrm{~min})$ breaks, plus the application and removal of electrodes.

\section{EEG Recording and Data Analysis}

Electroencephalographic (EEG) recordings were measured from the following scalp locations: F3, F4, C3, C4, P3, P4, O1, O2 (according to the 10-20 system), and the left and right mastoids (LM and RM, respectively). Horizontal eye movements were measured by recording the electrooculogram (EOG) between F7 and F8. Vertical EOG and eye movements were monitored between FP1 and an external electrode placed below the left eye. The common reference electrode was attached to the tip of the nose. The EEG was digitized at a $250-\mathrm{Hz}$ rate $(0.05-100 \mathrm{~Hz})$ and then filtered off line $(1-30 \mathrm{~Hz})$. The epochs used for averaging were $1,300 \mathrm{msec}$ long, starting $100 \mathrm{msec}$ before the onset of the visual stimulus and ending $1,200 \mathrm{msec}$ after. Thus, the epoch included the ERP response to the visual-auditory stimulus pair without overlap between pairs (see Figure 1). Epochs exceeding $\pm 100 \mu \mathrm{V}$ at any recording channel were rejected from subsequent processing, to remove trials that might be contaminated by an artifact of noncortical origin. Epochs were rejected from subsequent processing if the peak-to-peak signal exceeded $\pm 100 \mu \mathrm{V}$ at any electrode.

For each subject, the remaining epochs (there was a $10 \%$ rejection rate on the basis of the above criterion) were averaged separately by auditory stimulus type (standard pitch vs. deviant pitch). The ERP components (MMN, P3a, and RON) elicited by infrequent pitch changes were estimated separately for each condition by subtracting the ERP response to the visual-auditory stimulus pairs that included the standard-pitched tone from the ERP response to the pairs that included the deviant-pitched tone. In the predictable condition, the standard- and the deviant-pitched tones were matched with the frequent and the infrequent visual cues (respectively) so that the differences between the ERP responses evoked by the frequent versus the infrequent visual stimuli could also be displayed. However, in the unpredictable condition, the visual responses to the frequent and the infrequent stimuli could not be seen, because the auditory stimulus type was not matched with the visual stimulus type. Therefore, to display the visually evoked responses associated with the visual stimulus types for the unpredictable condition, the ERPs of this condition were separately averaged according to the stimulus type of the visual stimuli.

The mean amplitude in the 100 -msec prestimulus period was subtracted from each point of the averaged ERP responses. This prestimulus period served as the reference (biological zero), relative to which the stimulus-elicited electrical responses were measured.

To measure the mean amplitude of the ERP components, a 50msec window was used to obtain good signal-to-noise ratio, centered on the grand average of the deviant-minus-standard peak and determined for each component separately. The ERP responses in the unpredictable condition, in which all four ERP components were present (i.e., MMN, P3a, RON, and the visual P3b), were used to obtain the peak measurements. In this way, the mean amplitudes were measured using the following intervals for both (predictable and unpredictable) conditions. MMN was measured using the mean frontal amplitude in the 469- to 519-msec interval, relative to the onset of the visual stimulus (130 msec from tone onset); P3a was measured using the mean frontal amplitude in the 631- to 681-msec interval (297 msec from tone onset); RON was measured using the mean frontal amplitude in the 758 - to $808-\mathrm{msec}$ interval ( $435 \mathrm{msec}$ from tone onset); and the visual-evoked $\mathrm{P} 3 \mathrm{~b}$ was measured using the mean parietal amplitude in the 332- to 382-msec interval (relative to the onset of the visual stimulus).

Behavioral responses were considered correct if a response was recorded between 200 and 1,100 msec from the onset of the target tone. Repeated measures analyses of variance (ANOVAs) and onesample $t$ tests were used for statistical testing. Greenhouse-Geisser corrections were reported when applicable. Alpha was set at .05.

\section{RESULTS}

\section{Behavioral Results}

The subjects responded correctly to the longer duration tones on $84 \%$ ( $S E=7.5 \%)$ of the deviant-pitched and $90 \%(S E=4.7 \%)$ of the standard-pitched trials in the unpredictable condition and on $95 \%(S E=1.9 \%)$ of the deviant-pitched and $95 \%(S E=2.4 \%)$ of the standardpitched trials in the predictable condition.

The difference in RTs to the standard-pitched tones in the predictable versus unpredictable conditions was not significant [448 vs. $474 \mathrm{msec} ; t(8)=1.0, p=.33$ ]. This may be expected, because in both conditions, the visual stimuli informed the subjects that a tone was about to occur. In contrast, there was a significant difference in the RTs to deviant-pitched tones in the predictable versus unpredictable conditions. A distraction effect was observed in the unpredictable condition, in which no information about irrelevant pitch changes was provided by the visual stimuli. The subjects' RTs were significantly longer to the irrelevant deviant-pitched than to the standard-pitched tones ( 532 vs. $474 \mathrm{msec}$ ) in the unpredictable condition, whereas there was no significant difference in RTs between the irrelevant deviant- and standard-pitched tones in the predictable condition ( $461 \mathrm{vs} .448 \mathrm{msec}$ ). This was revealed by a significant interaction between stimulus type and condition $[F(1,8)=15.15, p<.0046]$. Furthermore, the mean RT difference between the deviant and the standards was significantly smaller for the predictable than for the unpredictable condition [13 vs. $58 \mathrm{msec} ; t(8)=3.9$, $p<.001$; see Figure 2).

\section{ERP Results}

The ERP responses elicited by the visual-auditory stimulus pairs were averaged according to the irrelevant pitch dimension of the sounds (standard and deviant pitches; Figure 3, top panel). Difference waveforms were obtained by subtracting the ERPs elicited by the standard-pitched tones from the ERPs elicited by the infrequent deviantpitched tones. These difference waveforms illustrate the ERP componentselicited in the unpredictableand the predictable conditions (Figure 3, bottom panel). MMNs, peaking at $130 \mathrm{msec}$ from tone onset, were present in both conditions $[t(8)=7.5, p<.001$, and $t(8)=5.0, p=0.001$, respectively] and did not differ in amplitude between the two conditions $[t(8)=1.3, p<.23]$. A prominent $\mathrm{P} 3 \mathrm{a}$, peaking $297 \mathrm{msec}$ from tone onset, followed by RON, peaking $435 \mathrm{msec}$ from tone onset, can be observed for the unpredictable condition, but not for the predictable condition (see Figure 3). One-sample $t$ tests show that the ERP components $\mathrm{P} 3 \mathrm{a}$ and RON were present in the unpredictable condition $[\mathrm{P} 3 \mathrm{a}, t(8)=5.0, p<.001 ; \mathrm{RON}, t(8)=3.4, p=$ $.009]$ and were absent in the predictable condition, where the ERP activity was not significantly different from zero [P3a, $t(8)<1, p=.88 ; \mathrm{RON}, t(8)<1, p=.84$ ]. The ERP components shown in Figure 3 (bottom panel) demonstrate the temporal sequence of cognitive brain processes elicited by unexpected irrelevant sound events. 


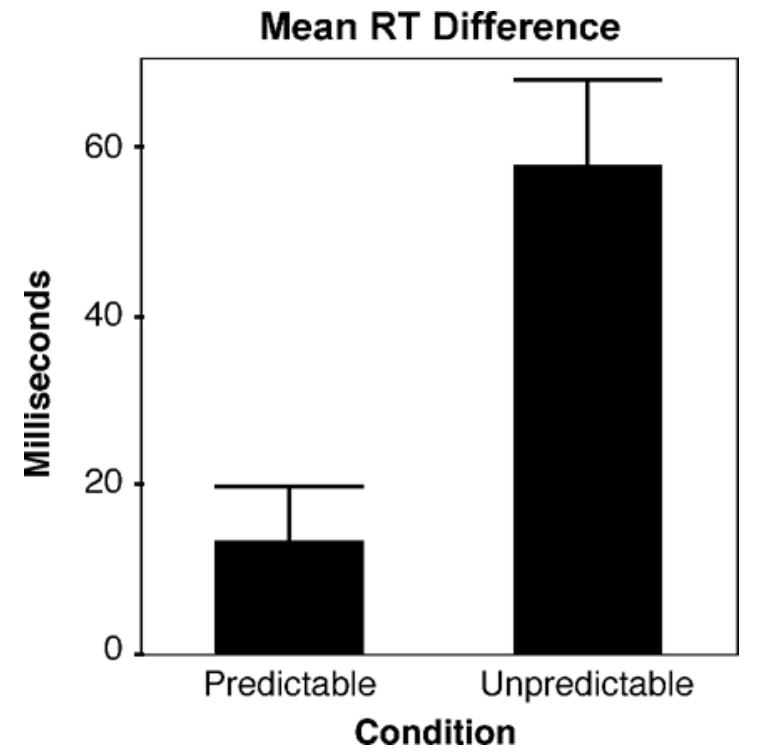

Figure 2. Mean reaction time (RT) difference. The mean RT to the deviant-pitched tones minus the mean RT to the standardpitched tones is shown for the predictable and the unpredictable conditions. An error bar displays the standard error of the mean. The RTs for the deviant-pitched targets were significantly longer than those for the standard-pitched targets in the unpredictable condition but were not significantly different in the predictable condition.

In both conditions, the deviant visual stimuli occurred unpredictably, eliciting a positive waveform peaking at $357 \mathrm{msec}$ from the onset of the visual stimulus [unpredictable, $t(8)=4.7, p<.001$; predictable, $t(8)=6.4, p<$ $.001]$. Both the latency and the scalp topography of this positive waveform were consistent with that of the $\mathrm{P} 3 \mathrm{~b}$ component (larger at parietal scalp sites), which is not directly associated with attentional control (Donchin \& Coles, 1988; Knight \& Scabini, 1998). Rare attended stimuli elicit the P3b component, as was the case for the present visual "deviants" (K. C. Squires, Donchin, Herning, \& McCarthy, 1977). The visual-evoked P3b appears in Figure 3 for the predictable condition only because the ERPs evoked by the stimulus pairs were averaged according to the pitch of the sounds. In the predictable condition, the visual-auditory pairs were matched by stimulus type: Deviant-pitched sounds were preceded by visual "deviants," and standard-pitched sounds were preceded by visual "standards." In the unpredictablecondition, the visualauditory pairs were not matched by stimulus type: deviantpitched sounds were preceded by both visual standards and deviants, as were standard-pitched sounds.

Figure 4 displays the visual P3b for both conditions. By separately averaging the ERPs according to the visual stimulus type for the unpredictable condition, we show the visual P3b for the unpredictable condition. The amplitude of the P $3 \mathrm{~b}$ elicited by the visual deviants in the predictable condition is larger than the $\mathrm{P} 3 \mathrm{~b}$ elicited by the visual deviants in the unpredictable condition. Figure 4 also shows that the visual responses did not overlap with the auditory responses, since there was no difference in the exogenous auditory response following the visual deviants.

\section{DISCUSSION}

We provide behavioral and electrophysiological evidence that predictability of irrelevant sound changes eliminates the distraction effect. When irrelevant pitch changes occurred unpredictably, all expected signs of the distraction effect were observed: prolonged RT to targets on deviant-pitched, as compared with standard-pitched, trials and elicitation of the ERP components P3a and RON. These results, for the unpredictable condition, are consistent with previous studies in which auditory distraction effects have been investigated(e.g., Schröger \& Wolff, 1998a, 1998b).

In contrast, when the subjects could predict the occurrence of the irrelevant pitch changes (using visual cues), no sign of distraction could be observed. The subjects' use of the visual cue maximized performance on the primary task in the predictable condition, avoiding the adverse effects of the irrelevant sound change on detecting the targets. Moreover, the ERP correlates of distraction were not elicited. These results demonstrate that voluntary processes influence the effects of sound changes on orienting of attention.

These results for auditory processing are most compatible with Yantis and Jonides (1990), who showed (Experiment 3) that only when attention was highly focused in advance of the target (i.e., visual cues had predictive validities occurring at a fixed temporal interval) were the abrupt onsets resistant to attentional capture. That is, only when the distractors occurred with $100 \%$ predictive validity to a cued location (as in the predictable condition of the present experiment, in which the auditory distractors were preceded by $100 \%$ valid cues) could involuntary attention switching be abated. When cues were not predictive, abrupt onsets captured attention (as was shown for the unpredictablecondition in the present experiment). Although pitch changes do not in and of themselves capture attention (MMN can be elicited without P3a), when attention is focused on the sounds to perform a task with them, it is possible that changes in an irrelevant dimension (e.g., pitch changes) act as abrupt onsets in the current auditory scene. The results of the present study are consistent with top-down control over stimulus-driven switching of attention.

MMNs of similar amplitude and latency were elicited by the infrequent pitch changes in both the predictable and the unpredictable conditions, showing that the small pitch changes were detected even though they were irrelevant for the task. Furthermore, it reveals that the detection process reflected by MMN was unaffected by the subjects' conscious expectations. This result is consistent with those obtained in studies that show that higher level cognitive processes related to expectancy or conscious prediction of auditory events do not play a role in the $\mathrm{MMN}$ generating process (Rinne, Antila, \& Winkler, 2001; Ritter, Sussman, Deacon, Cowan, \& Vaughan, 1999). In the present study, within the process of involuntary orienting to irrelevant sounds, the stage reflecting the stimulus- 


\section{Unpredictable Condition}
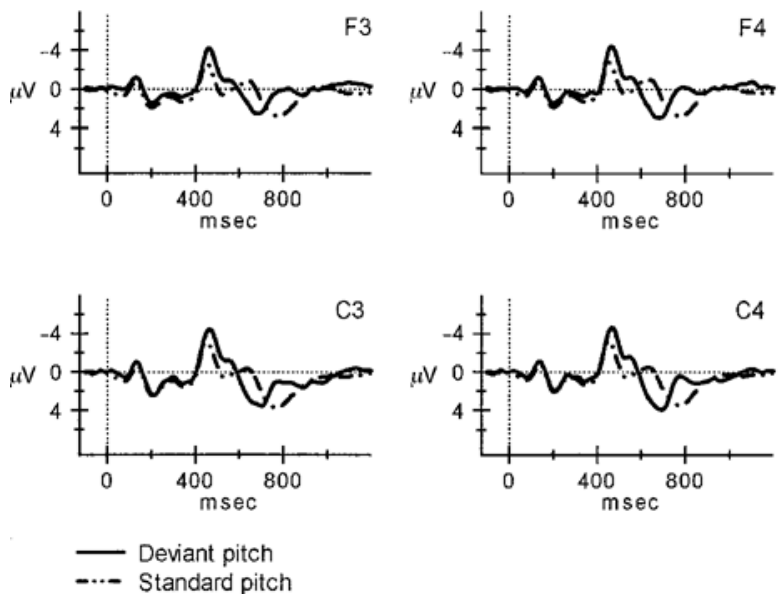

\section{Predictable Condition}
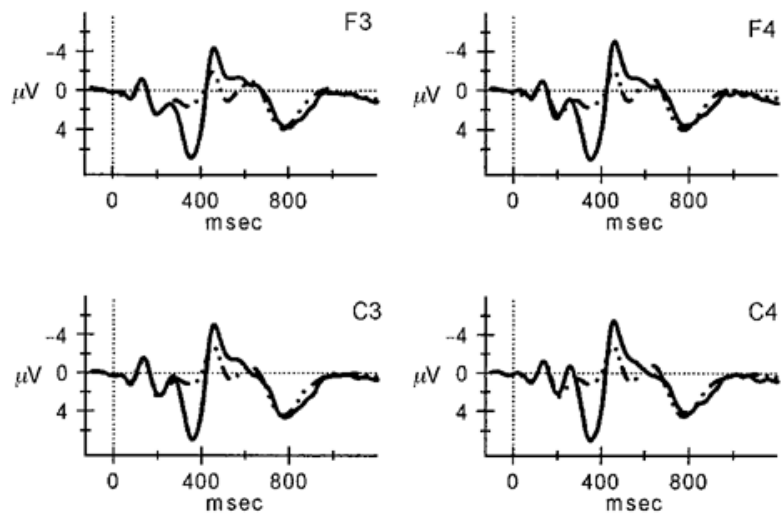

C4
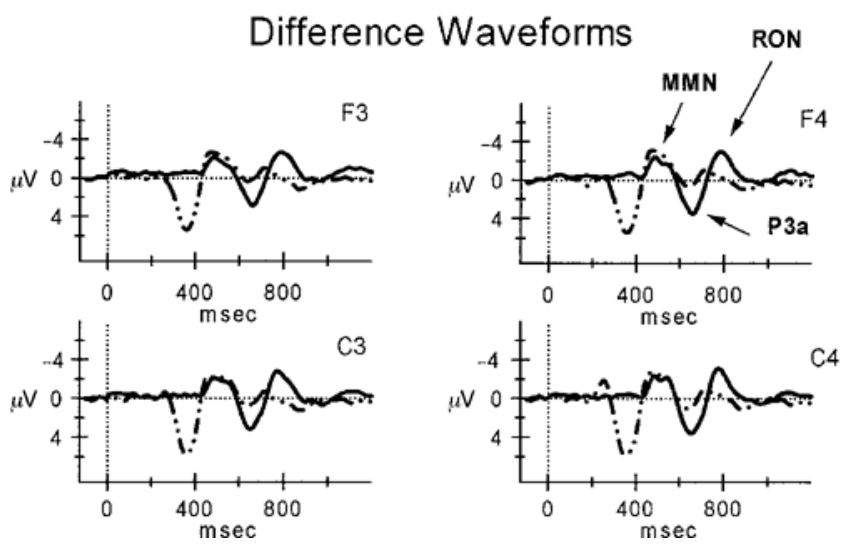

- Unpredictable Condition

-..- Predictable Condition

Figure 3. Grand-averaged electrical brain responses elicited at frontal (F3 and F4) and central (C3 and C4) scalp locations are shown, averaged according to the pitch of the tones (see the Method section for a detailed description): the event-related brain potentials (ERPs) elicited by the deviant-pitched (solid lines) and the standard-pitched (stippled lines) tones for the predictable (top right panel) and the unpredictable (top left panel) conditions. Difference waveforms obtained by subtracting the brain responses elicited by the standard-pitched tones from the brain responses elicited by the deviant-pitched tones for the predictable (stippled lines) and the unpredictable (solid lines) conditions are displayed in the bottom panel. Arrows point to the mismatched negativity, which was elicited in both conditions, and to the P3a and reorienting negativity ERP components, which were elicited only in the unpredictable condition.

driven detection of the deviant event was not affected by predictability, but the stage of attention switching was.

The amplitude of the P3b component elicited by the infrequent visual stimuli in the predictable condition was larger than the amplitude of the P3b elicited by the infrequent visual stimuli in the unpredictable condition. This amplitude difference resulted because of a difference in the processing of the visual cues themselves. In the unpredictable condition, the rare visual stimuli made available less information than they did in the predictable condition. In the predictable condition, the rare visual stimuli provided two pieces of information: They indicated that a tone was about to occur, and they denoted the pitch of the tone. In the unpredictable condition, the rare visual stimuli informed the subjects only that a tone was forthcoming. Therefore, the relevance of the rare visual stimulus events for accurately performing the task was larger in the predictable condition. P3 amplitude is positively affected by the subjective stimulus relevance (or utility) of rare events (Coles, Smid, Scheffers, \& Otten, 1995; Duncan-
Johnson \& Donchin, 1977; Gratton et al., 1990; Johnson \& Donchin, 1978). This difference at the level of visual processing, reflected in the amplitude of the P3b, did not overlap with auditory processing, since no difference in the exogenous auditory response (N1 component) could be observed between these two conditions.

The results demonstrate how a complex series of processes can be delineated by ERPs. The ERP responses observed in the present study reflect a series of cognitive events triggered by the occurrence of a task-irrelevant sound change, each associated with a different step in the distraction effect. The automatic change detection system remained responsive (i.e., MMN was elicited) whether or not the change was expected. However, not every sound change (detected by the automatic system) causes a switch of attention: MMN can be elicited by unattended and unpredictable sound changes without an ensuing P3a (Lyytinen, Blomberg, \& Näätänen, 1992). This suggests that $\mathrm{P} 3 \mathrm{a}$ and RON are not automatic consequences of any unpredictable stimulus event but are probably evoked 


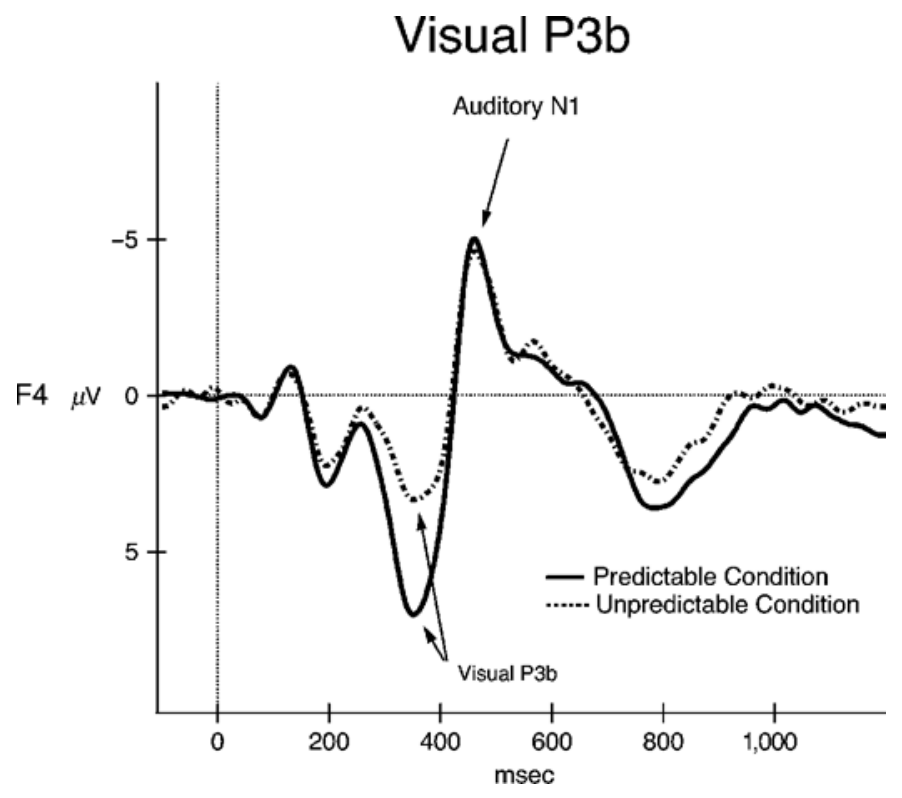

Figure 4. Visually evoked $P 3$. The visually evoked response to the infrequent visual stimuli for the predictable (solid line) and the unpredictable (dotted line) conditions are shown, followed by the exogenous auditory response (N1) to the following tone.

when the change signal exceeds some variable threshold (Schröger, 1997) that depends both on the amount of change (e.g., novel stimuli cause a larger change signal; Näätänen, 1992) and on whether the irrelevant changes occur in an attended or an unattended modality (see Escera et al., 2000). It is possible that the top-down control over task-irrelevant change detection, which was demonstrated in the present study, acts by temporarily raising the threshold of attention switching. Furthermore, P3a can occur without RON (e.g., when all of the auditory stimuli are irrelevant to the task; Escera, Alho, Winkler, \& Näätänen, 1998). RON follows P3a when the eliciting stimulus itself is relevant to the task, although the distracting dimension of the stimulus is irrelevant. It appears that these ERP components reflect separate processes, which do not automatically follow each other, and thus allow us to identify the time course of a series of cognitive events within the processing of task-irrelevant acoustic deviance.

Unexpected or sudden sound changes distract us. The present results show that determining the relevance of a sound prior to its occurrence can suppress the involuntary orienting of attention, which could conserve attentional resources for the task of relevance to the organism. The results provide evidence of top-down influence on behavioral and electrophysiological responses associated with orienting and reorienting of attention.

\section{REFERENCES}

Ahveninen, J., JäÄSkeläinen, I. P., Pekronen, E., Hallberg, A., Hietanen, M., NäÄtänen, R., Schröger, E., \& Sillanaukee, P. (2000). Increased distractibility by task-irrelevant sound changes in abstinent alcoholics. Alcoholism: Clinical \& Experimental Research, 24, 1850-1854.
Alho, K., Escera, C., Diaz, R., Yago, E., \& Serra, J. M. (1997). Effects of involuntary auditory attention on visual task performance and brain activity. NeuroReport, 8, 3233-3237.

Berti, S., \& Schröger, E. (2001). A comparison of auditory and visual distraction effects: Behavioral and event-related indices. Cognitive Brain Research, 11, 265-273.

Coles, M. G. H., Smid, M., Scheffers, M. K., \& Otten, L. J. (1995). Mental chronometry and the study of human information processing. In M. D. Rugg \& M. G. H. Coles (Eds.), Electrophysiology of mind: Event-related brain potentials and cognition (pp. 86-131). New York: Oxford University Press.

Courchesne, E., Hillyard, S. A., \& Galambos, R. (1975). Stimulus novelty, task relevance, and the visual evoked potential in man. Electroencephalography \& Clinical Neurophysiology, 39, 131-143.

CséPe, V., Karmos, G., \& Molnar, M. (1987). Evoked potential correlates of stimulus deviance during wakefulness and sleep in cat-animal model of mismatch negativity. Electroencephalography in Clinical Neurophysiology, 66, 571-578.

Donchin, E., \& Coles, M. (1988). Is the P300 component a manifestation of context updating? Behavioral \& Brain Sciences, 11, 357-374.

Driver, J., \& BAY LIS, G. C. (1991). Target-distractor separation and feature integration in visual attention to letters. Acta Psychologica, 76, 101-119.

Duncan-Johnson, C. C., \& Donchin, E. (1977). On quantifying surprise: The variation of event-related potentials with subjective probability. Psychophysiology, 14, 456-467.

Escera, C., Alho, K., Schröger, E., \& Winkler, I. (2000). Involuntary attention and distractibility as evaluated with event-related brain potentials. Audiology \& Neuro-Otology, 5, 151-166.

Escera, C., AlHo, K., WinkLer,I., \& NÄÄTÄNEN, R. (1998). Neural mechanisms of involuntary attention switching to novelty and change in the acoustic environment. Journal of Cognitive Neuroscience, 10, 590-604.

Escera, C., Yago, E., \& Alho, K. (2001). Electrical responses reveal the temporal dynamics of brain events during involuntary attention switching. European Journal of Neuroscience, 14, 877-883.

Folk, C. L., \& Remington, R. W. (1996). When knowledge doesn't help: Limitations on the flexibility of attentional control. In A. F. Kramer, M. G. H. Coles, \& G. D. Logan (Eds.), Converging operations in the study of visual selective attention (pp. 271-295). Washington, DC: American Psychological Association. 
Folk, C. L., \& Remington, R. W. (1998). Selectivity in distraction by irrelevant featural singletons: Evidence for two forms of attentional capture. Journal of Experimental Psychology: Human Perception \& Performance, 24, 847-858.

Folk, C. L., Remington, R. W., \& Johnston, J. C. (1992). Involuntary covert orienting is contingent on attentional control settings. Journal of Experimental Psychology: Human Perception \& Performance, 18, 1030-1044.

Friedman, D., Cycowicz, Y. M., \& Gaeta, H. (2001). The novelty P3: An event-related brain potential (ERP) sign of the brain's evaluation of novelty. Neuroscience \& Biobehavioral Reviews, 25, 355-373.

Giard, M. H., Perrin, F., Pernier, J., \& Bouchet, P. (1990). Brain generators implicated in processing of auditory stimulus deviance: A topographic event-related potential study. Psychophysiology, 27, 627-640.

Gratton, G., Bosco, C. M., Kramer, A. F., Coles, M. G. H., WickENS, C. D., \& Donchin, E. (1990). Event-related brain potentials as indices of information extraction and response priming. Electroencephalography \& Clinical Neurophysiology, 75, 419-432.

Halgren, E., Baudena, P., Clarke, J. M., Heit, G., Liegeois, C., Chauvel, P., \& Musolino, A. (1995). Electroencephalography \& Clinical Neurophysiology, 94, 191-220.

Javitt, D. C., Steinschneider, M., Schroeder, C. E., \& Arezzo, J. C. (1996). Detection of stimulus deviance within primate primary auditory cortex: Intracranial mechanisms of mismatch negativity (MMN) generation. Brain Research, 667, 192-200.

Johnson, R., JR., \& Donchin, E. (1978). On how P300 amplitude varies with the utility of the eliciting stimuli. Electroencephalography \& Clinical Neurophysiology, 44, 424-437.

Jonides, J., \& YANTIS, S. (1988). Uniqueness of abrupt visual onset in capturing attention. Perception \& Psychophysics, 43, 346-354.

KNight, R. T. (1991). Evoked potential studies of attention capacity in human frontal lobe lesions. In H. S. Levin, H. M. Eisenberg, \& A. L. Benton (Eds.), Frontal lobe function and dysfunction (pp. 139153). New York: Oxford University Press.

KNight, R. T., \& Scabini, D. (1998). Anatomic bases of event-related potentials and their relationship to novelty detection in humans. Journal of Clinical Neurophysiology, 15, 3-13.

Kramer, A. F., \& JACOBSON, A. (1991). Perceptual organization and focused attention: The role of objects and proximity in visual processing. Perception \& Psychophysics, 50, 267-284.

Kropotov, J. D., Nä̈̈̈ӓ̈nen, R., Sevostianov, A. V., Alho, K., Reinkainen, K., \& Kropotova, O. V. (1995). Mismatch negativity to auditory stimulus change recorded directly from the human temporal cortex. Psychophysiology, 32, 418-422.

Lyytinen, H., Blomberg, A. P., \& Nä̈̈tänen, R. (1992). Eventrelated potentials and autonomic responses to a change in unattended auditory stimuli. Psychophysiology, 29, 523-534.

Müller, H. J., \& RabBitt, P. M. A. (1989). Reflexive and voluntary orienting of visual attention: Time course of activation and resistance. Journal of Experimental Psychology: Human Perception \& Performance, 15, 315-330.

NÄÄTÄNEN, R. (1992). Attention and brain function. Hillsdale, NJ: Erlbaum.

NÄÄTÄNEN, R, \& WiNKLER, I. (1999). The concept of auditory stimulus representation in cognitive neuroscience. Psychological Bulletin, 6, 826-859.

Nagahama, Y., OKada, T., Katsumi, Y., Hayashi, T., Yamauchi, H., Oyanagi, C., Konishi, J., Fukuyama, H., \& Shibasaki, H. (2001). Dissociable mechanisms of attentional control within human prefrontal cortex. Cerebral Cortex, 11, 85-92.

Opitz, B., Rinne, T., Mecklinger, A., von Cramon, D. Y., \& SCHRÖGER, E. (2002). Differential contribution of frontal and temporal cortices to auditory change detection: fMRI and ERP results. NeuroImage, 15, 165-174.

Picton, T. W., Alain, C., Otten, L., Ritter, W., \& Achim, A. (2000). Mismatch negativity: Different water in the same river. Audiology \& Neuro-Otology, 5, 111-139.

Remington, R. W., Folk, C. L., \& McLean, J. P. (2001). Contingent attentional capture or delayed allocation of attention? Perception \& Psychophysics, 63, 298-307.

Remington, R. W., Johnston, J. C., \& Yantis, S. (1992). Involuntary attentional capture by abrupt onsets. Perception \& Psychophysics, 51, 279-290.
Rinne, T., Alho, K., Ilmoniemi, R. J., Virtanen, J., \& NäÄtÄnen, R. (2000). Separate time behaviors of the temporal and frontal MMN sources. NeuroImage, 12, 14-19.

Rinne, T., Antila, S., \& Winkler, I. (2001). MMN is unaffected by top-down predictive information. NeuroReport, 12, 2209-2213.

Ritter, W., Sussman, E., Deacon, D., Cowan, N., \& Vaughan,H. G., JR. (1999). Two cognitive systems simultaneously prepared for opposite events. Psychophysiology, 36, 835-838.

SAMS, M., \& HARI, R. (1991). Magnetoencephalography in the study of human auditory information processing. In R. A. Zapulla et al. (Eds.), Windows on the brain: Neuropsychology's technical frontiers (Annals of the New York Academy of Sciences, Vol. 620, pp. 102-117). New York: New York Academy of Sciences.

Scherg, M., Vajsar, J., \& Picton, T. W. (1989). A source analysis of the late human auditory evoked potentials. Journal of Cognitive Neuroscience, 1, 336-355.

SCHröger, E. (1997). On the detection of auditory deviations: A preattentive activation model. Psychophysiology, 34, 245-257.

Schröger, E., Giard, M.-H., \& WolfF, C. (2000). Auditory distraction: Event-related potential and behavioral indices. Clinical Neurophysiology, 111, 1450-1460.

Schröger, E., \& WolfF, C. (1998a). Attentional orienting and reorienting is indicated by human event-related brain potentials. NeuroReport, 9, 3355-3358.

Schröger, E., \& WolfF, C. (1998b). Behavioral and electrophysiological effects of task-irrelevant sound change: A new distraction paradigm. Cognitive Brain Research, 7, 71-87.

Spencer, K. M., Dien, J., \& Donchin, E. (1999). A componential analysis of the ERP elicited by novel events using a dense electrode array. Psychophysiology, 36, 409-414.

Squires, K. C., Donchin, E., Herning, R. I., \& McCarthy, G. (1977). On the influence of task relevance and stimulus probability on eventrelated potential components. Electroencephalography \& Clinical Neurophysiology, 42, 1-14.

Squires, N. K., Squires, K. C., \& Hillyard, S. A. (1975). Two varieties of long-latency positive waves evoked by unpredictable auditory stimuli in man. Electroencephalography \& Clinical Neurophysiology, 38, 387-410.

Sutton, S., Braren, M., Zubin, J., \& John, E. R. (1965). Evoked potential correlates of stimulus uncertainty. Science, 150, 1187-1188.

Theeuwes, J. (1991). Cross-dimensional perceptual selectivity. Perception \& Psychophysics, 50, 184-193.

Theeuwes, J. (1992). Perceptual selectivity for color and form. Perception \& Psychophysics, 51, 599-606.

Theeuwes, J. (1994). Stimulus-driven capture and attentional set: Selective search for color and visual abrupt onsets. Journal of Experimental Psychology: Human Perception \& Performance, 20, 799-806.

Theeuwes, J., \& Berger, R. (1998). Attentional control during visual search: The effect of irrelevant singletons. Journal of Experimental Psychology: Human Perception \& Performance, 24, 1342-1353.

Treisman, A. M., \& Gelade, G. (1980). A feature integration theory of attention. Cognitive Psychology, 12, 97-136.

Woods, D. L. (1990). The physiological basis of selective attention: Implications of event-related potential studies. In J. W. Rohrbaugh, R. Parasuranam, \& R. Johnson, Jr. (Eds.), Event-related potentials: Basic issues and applications (pp. 178-209). New York: Oxford University Press.

YANTIS, S. (1993). Stimulus-driven attentional capture and attentional control settings. Journal of Experimental Psychology: Human Perception \& Performance, 19, 676-681.

Yantis, S., \& EGeth, H. E. (1999). On the distinction between salience and stimulus-driven attentional capture. Journal of Experimental Psychology: Human Perception \& Performance, 25, 661-676.

YANTIS, S., \& JonIDES, J. (1984). Abrupt visual onsets and selective attention: Evidence from visual search. Journal of Experimental Psychology: Human Perception \& Performance, 10, 601-621.

YANTIS, S., \& Jonides, J. (1990). Abrupt visual onsets and selective attention: Voluntary versus automatic allocation. Journal of Experimental Psychology: Human Perception \& Performance, 16, 121-134.

(Manuscript received August 23, 2001; revision accepted for publication May 31, 2002.) 